\title{
O FENÔMENO DA CAPTURA E A INDEPENDÊNCIA DAS AGÊNCIAS REGULADORAS NO BRASIL
}

\author{
Vitor Gabriel Garnica ${ }^{1}$ \\ Marlene Kempfer ${ }^{2}$
}

\section{Resumo:}

A pesquisa desenvolve o tema das agências reguladoras que são órgãos públicos submetidos a um regime jurídico especial. Este indica a independência de sua composição e de atuação como condição de legalidade e de legitimidade. Aponta-se o fenômeno da captura, que poderá ocorrer naqueles dois momentos, como sendo uma forma de corrupção a desestabilizar o modelo das agências implementado no Brasil a partir de 1997. O percurso dos estudos considera método qualitativo a partir da doutrina e da legislação em vigor.

Palavras-Chaves: Agências Reguladoras; atividade regulatória; fenômeno da captura; Lei $\mathrm{n}^{\circ}$ 13.848/19; autarquias de regime especial.

\section{CAPTURE THEORY AND INDEPENDENCY OF REGULATORY AGENCYS IN BRAZIL}

\begin{abstract}
:
The research develops the theme of regulatory agencies that are public agencies subject to a special legal regime. This indicates the independence of its composition and performance as a condition of legality and legitimacy. The phenomenon of capture, which may occur at those two moments, is shown as a form of corruption destabilizing the agency model implemented in Brazil since 1997. The course of studies considers a qualitative method based on the doctrine and currently legislation.
\end{abstract}

Keys-Words: Regulatory agencies; regulatory activity; capture theory; Law No 13.848/19; special regime autarchy.

\section{INTRODUÇÃO}

As agências reguladoras e a atividade regulatória estruturam-se dentro do contexto internacional e nacional.

\footnotetext{
${ }^{1}$ Mestrando do Programa de Direito Negocial da Universidade Estadual de Londrina. Bolsista pela CAPES. Endereço eletrônico: vitorgarnica@ hotmail.com. http://lattes.cnpq.br/5990451598884333.

${ }^{2}$ Doutora e Mestre em Direito do Estado pela Pontifícia Universidade Católica de São Paulo (PUC/SP). Professor da graduação em Direito e do Programa de Mestrado em Direito Negocial da Universidade Estadual de Londrina. Endereço eletrônico: mkempferb@gmail.com. http://lattes.cnpq.br/7141753184018389
} 
A globalização é aspecto determinante para entender as transformações substanciais após o século XX. É impossível compreender uma conjectura se esta não está aliada as relações internacionais, sejam elas recíprocas ou de dominação. Assim, o Estado em constante transformação (Estado Social-Democrático para o Estado Neoliberal) adotou novas políticas que norteariam os interesses globais em uma economia interligada e interdependente. A nova proposta do cenário mundial seria a diminuição do Estado frente as relações sociais existentes, porém o Liberalismo do século XVIII (inaugurado teoricamente pelo economista Adam Smith em 1776) já não era mais compatível aos moldes das relações contemporâneas, seja entre os Estados e entre os indivíduos. Assim, como resposta para a solução dos problemas do século XVIII, põe-se o Estado como mediador desta economia liberal. Então, o Estado torna-se fiscalizador das práticas econômicas, incentivador para condutas que replicam a boa sociabilidade e planejador para a efetividade e consecução das atividades propostas pela sociedade, utilizando-se das suas competências normativas e regulatórias. Assim, a Constituição Federal de 1988 dispõe, no que tange as relações econômicas, em seu art. 174, evidenciando a visão do constituinte para o contexto então vigente.

A Reforma da Gestão Pública pela emenda constitucional no 19 de 1998 é um marco administrativo para a ampliação das demandas sociais existentes, no qual em linhas gerais, confere uma maior democracia, participação popular, controle, transparência, universalização, neutralidade, eficácia e eficiência. A fim de conferir eficácia segundo aos moldes da reconfiguração do Estado cria-se as Agências Reguladoras como instrumento jurídico e administrativo para a execução da política econômica regulatória. Pode-se dizer que a necessidade das agências reguladoras para a atividade regulatória antecede este marco constitucional, como se observa nas leis instituidoras da ANNEL (Agência Nacional de Energia Elétrica - Lei no 9.427/96), da ANATEL (Agência Nacional de Telecomunicações Lei $n^{\circ}$ 9.472/97) e da ANP (Agência Nacional do Petróleo - Lei $n^{\circ}$ 9.478/97). Amparadas pelos critérios da racionalidade e da técnica, as agências reguladoras tem funções essenciais para a consolidação de políticas públicas e regulatória do Estado.

As agências reguladoras são instituídas por lei e cada uma possui sua própria configuração. No Brasil, inexistia até 25 de Junho de 2019 uma Lei Geral sobre as Agências Reguladoras. A Lei n 13.848 de 2019 veio para suprir esta lacuna que estava faltando. Neste artigo pretende-se abordar sobre as principais disposições dessa lei que afeta todas as 11 agências reguladoras em âmbito federal. 
Por fim, tendo como recorte central da pesquisa o fenômeno da captura, há de se falar sobre as formas de captação política e econômica das quais as agências brasileiras estão sujeitas e de qual modo isso afeta a independência delas, pressuposto indispensável para a consolidação de políticas regulatórias em prol do interesse comum.

\section{AS AGÊNCIAS REGULADORAS COMO AUTARQUIAS ESPECIAIS.}

As agências reguladoras serão o objeto a ser analisado neste artigo. Para a compreensão e elucidação da problemática a ser levantada, a questão do fenômeno da captura e como tal fato incide na independência e na teleologia desta política regulatória.

A fim de elucidar e moldurar as agências reguladoras trata-se o conceito, a sua natureza jurídica e regime jurídico (diferenciação entre autarquia e autarquia sob regime especial); as suas duas classificações das atividades regulatórias; suas características fundamentais e; por fim, suas competências.

A gênese das agências reguladoras está contemplado na Constituição Federal de 1988, no qual consagra em seu Artigo $173^{3}$ a legitimidade do Estado em atuar, juntamente ao setor privado para os relevantes casos de segurança nacional e ao interesse coletivo. Assim segue a Constituição em delimitar as prerrogativas e competências do Estado frente a regulação da economia, delimitando a proposta do Estado Regulador ${ }^{4}$. Assim, os Artigos $174^{5}$ e 175 , caput $^{6}$, legitimam a instauração dos marcos regulatórios no Brasil, tendo como natureza jurídica personalizada nas Agências Reguladoras, estas que possuem função estratégica nos setores econômicos e na prestação de serviços públicos concedidos pelo Estado. Portanto, a fim de delimitar o conceito, traz-se o princípio finalístico da atividade regulatória, que seja regular mercados, a fim de trazer competitividade ao setor regulado, gerando serviços públicos de qualidade, além de expandir a prestação de serviço ofertado pelo

\footnotetext{
${ }^{3}$ Art. 173. Ressalvados os casos previstos nesta Constituição, a exploração direta de atividade econômica pelo Estado só será permitida quando necessária aos imperativos da segurança nacional ou a relevante interesse coletivo, conforme definidos em lei

4 “ “...] no novo Estado social-liberal, a tendência geral continuará a ser de mais regulação, porque os principais objetivos da regulação são defender a competição e proteger o consumidor”. (BRESSER-PEREIRA, 2009 , p. 160)

5 Art. 174. Como agente normativo e regulador da atividade econômica, o Estado exercerá, na forma da lei, as funções de fiscalização, incentivo e planejamento, sendo este determinante para o setor público e indicativo para o setor privado

${ }^{6}$ Art. 175. Incumbe ao Poder Público, na forma da lei, diretamente ou sob regime de concessão ou permissão, sempre através de licitação, a prestação de serviços públicos.
} 
setor regulado para o maior número de pessoas, refletindo sobre a finalidade do Ente Público: o princípio do Interesse Coletivo (MARQUES NETO, p. 35/36)

A natureza jurídica das agências reguladoras nasce sob a ótica existente que concebia a definição do direito positivado de autarquias, conforme estabelece o Decreto-Lei $n^{\text {o }}$ 200/67, art. 5 ${ }^{\text {, inciso I }}{ }^{7}$. O doutrinador e Professor Hely Lopes Meirelles (2016, p. 70) conceitua as Entidades Autárquicas como:

[...] pessoas jurídicas de Direito Público, de natureza meramente administrativa, criadas por lei específica, para a realização de atividades, obras ou serviços descentralizados da entidade estatal que as criou. Funcionam e operam na forma estabelecida na lei instituidora e nos termos de seu regulamento [...]. As autarquias podem desempenhar atividades educacionais, previdenciárias e quaisquer outras outorgadas pela entidade estatal matriz, mas sem subordinação hierárquica, sujeitas apenas ao controle finalístico de sua administração e da conduta de seus dirigentes.

Dentro deste entendimento, compreende-se que como autarquias, as agências reguladoras, de acordo com a Constituição Federal, em seu art. 37, inciso XIX ${ }^{8}$, assim complementa o Ministro Alexandre de Moraes (2002, p. 24): “[...] que somente por lei específica poderá ser criada autarquia; que, em face da incidência do princípio da especialidade, não poderá afastar-se, no exercício de suas atividades, das finalidades e dos objetivos determinadas na lei de sua criação".

Portanto, o regime jurídico de autarquias de regime especial foi a escolha do legislador sobre as agências reguladoras. Porém, a qualificação dada a elas, sob o enfoque de serem de regime especial tem o intuito de garantir, não só as prerrogativas das autarquias de maneira geral, mas de reforçar a ideia de autonomia que garantem o livre exercício ${ }^{9}$ para a

\footnotetext{
${ }^{7}$ Art. $5^{\circ}$ Para os fins desta lei, considera-se: I - Autarquia - o serviço autônomo, criado por lei, com personalidade jurídica, patrimônio e receita próprios, para executar atividades típicas da Administração Pública, que requeiram, para seu melhor funcionamento, gestão administrativa e financeira descentralizada.

${ }^{8}$ Art. 37. A administração pública direta e indireta de qualquer dos Poderes da União, dos Estados, do Distrito Federal e dos Municípios obedecerá aos princípios de legalidade, impessoalidade, moralidade, publicidade e eficiência e, também, ao seguinte:

XIX - somente por lei específica poderá ser criada autarquia e autorizada a instituição de empresa pública, de sociedade de economia mista e de fundação, cabendo à lei complementar, neste último caso, definir as áreas de sua atuação;

9 "Todavia, por outro lado, parece claro que mesmo a lei não poderá dispensar a agência reguladora dos controles financeiros/orçamentários estatais, prévios ou não, externos (Poder Legislativo, Tribunais de Contas, controle jurisdicional) ou internos (leis gerais sobre Administração indireta, como o Decreto-lei $n^{\circ}$ 200/67, área federal; Decreto-lei Complementar $\mathrm{n}^{\circ} 7 / 69$, no Estado de São Paulo), como até já se tentou incluir em lei criadora de agência, pois o controle citado tem assento constitucional (CF, arts. 49, X; 70; 71; 163, II e 165, §5 ), e tais agências também se aplica o princípios da tutela, como a qualquer autarquia.” (DI PIETRO, 1999, p. 397)
} 
consolidação e efetivação das políticas regulatórias. Perante esse novo status, a reconfiguração para Estado Regulador, tem-se:

Com a política governamental de transferir para o setor privado a execução de serviços públicos, reservando ao Estado a regulamentação, o controle e a fiscalização desses serviços, houve a necessidade de criar, na Administração, agências especiais destinadas a esse fim, no interesse dos usuários e da sociedade. Tais agências têm sido denominadas de agências reguladoras e foram instituídas como autarquias sob regime especial, com o propósito de assegurar sua autoridade e autonomia administrativa. Com essa finalidade, a Lei 9.427, de 26.12.96, instituiu a Agência Nacional de Energia Elétrica ANEEL, para regular e fiscalizar o setor de geração, transmissão e distribuição de energia elétrica; e a Lei 9.472, de 16.7.97, criou a Agência Nacional de Telecomunicações -ANATEL, com o mesmo objetivo em relação ao setor de telecomunicações, porque ambas as áreas estão sendo privatizadas. (MEIRELLES, 2016, p. 449/450)

Dentre as autarquias sob regime especial, as agências reguladoras possuem duas classificações de regulação que devem ser abordadas: i) de serviços públicos e ii) da atividade econômica em sentido estrito (SILVA, 2010, p. 110). As autarquias federais de regulação de serviços públicas são aquelas que desempenham papel estratégico para o Estado (BRESSERPEREIRA, 2009, p. 307), entre elas: Agência Nacional de Telecomunicações (ANATEL), Agência Nacional de Energia Elétrica (ANEEL), Agência Nacional do Cinema (ANCINE), Agência Nacional de Aviação Civil (ANAC), Agência Nacional de Transportes Terrestres (ANTT) e; as agências reguladoras da atividade econômica em sentido estrito são: Agência Nacional do Petróleo (ANP), Agência Nacional de Vigilância Sanitária (ANVISA), Agência Nacional de Saúde Suplementar (ANS), Agência Nacional das Águas (ANA). A importância em classificá-las deriva-se do grau de atuação do Estado, “em suma, a margem da liberdade do órgão regulador de serviços públicos é maior do que aquela conferida ao órgão regulador da atividade econômica privada" (SILVA, 2004, p. 112).

Delimitando o campo de ação das agências, assim como sua natureza jurídica e regime jurídico, o Professor Doutor Floriano Peixoto de Azevedo Marques Neto (2005, p. 47) em seus estudos desenvolve importante pontuações no que concerne sobre as características e competências das agências reguladoras, temos:

Destas condicionantes resultam as características essenciais daqueles entes estatais que deverão se incumbir da regulação estatal, a saber: i) serem órgãos públicos; ii) que concentrem várias funções e competências; iii) voltadas para um setor da economia que demande significativa especialização; iv) marcados pela busca de equilíbrio entre interesses 
envolvidos com a atividade regulatória e v) que tenham uma significativa neutralidade em relação a estes interesses.

Também, utilizando o mesmo entendimento, o referido autor (2005, pgs. 60 e 61) prossegue ao elucidar e elencar seis competências que são prerrogativas das agências (de modo geral), conforme exemplifica:

Embora isso possa variar de setor para setor, as agências reúnem os seguintes poderes: i) poder normativo, consistente em editar comandos gerais para o setor regulado (complementando os comandos legais crescentemente abertos e indefinidos); ii) poder de outorga, consistente na prerrogativa de emissão, de atos concertos de licenças, autorizações, injunções, com vistas a franquear ou interditar o exercício de uma atividade regulada a um particular; iii) poder de fiscalização do setor, a qual se revela tanto pelo monitoramento das atividades reguladas (de modo a manter-se permanentemente informada sobre as condições econômicas, técnicas e de mercado do setor), quanto na aferição das condutas dos regulados de modo a impedir o descumprimento de regras ou objetivos regulatórios; iv) poder sancionatório, consistente tanto na aplicação de advertências, multas ou mesmo cassações de licenças, como também na prerrogativa de obrigas o particular a reprarar um consumidor ou corrigir efeitos de uma conduta lesiva a algum valor ou interesse tutelado pelo regulador; v) poder de conciliação, que se traduzem na capacidade de, dentro do setor, conciliar ou mediar interesses de operadores regulados, consumidores isolados ou em grupos de interesses homogêneos, ou ainda interesses de agentes econômicos que se relacionam com o setor regulado (malgrado não explorarem diretamente a atividade sujeita à regulação setorial) no âmbito da cadeia econômica; e por fim vi) poderes de recomendação, consistentes na prerrogativa, muitas vezes previstas na lei que cria a agência, de o regulador subsidiar, orientar ou informar o poder político, recomendando medidas ou decisões a serem editadas no âmbito das políticas públicas.

Portanto, forma-se o entendimento em linhas gerais no que concerne a ideia jurídicalegal das agências reguladoras, assim como a delimitação do campo de atuação do qual o Estado confere prerrogativas a estes Entes Autárquicos sob regime especial. Porém, para a consolidação e efetividade da atividade regulatória os pressupostos da autonomia não se fazem suficientes para dentro da problemática brasileira. A independência supõe a autonomia deste órgãos, além da não interferência política e do setor regulado. A doutrina cunha essa ingerência como o Fenômeno da Captura e possui traços característicos do nosso processo histórico-político.

\section{O IMPEDIMENTO DA INDEPENDÊNCIA DAS AGÊNCIAS FRENTE AO FENÔMENO DA CAPTURA.}


$\mathrm{O}$ aspecto referencial deste artigo visa a independência das Agências frente ao fenômeno da captura. A fim de delimitar a temática, tem-se a discussão sobre a diferenciação entre autonomia e a independência, sendo que para a efetivação da segunda depende dos pressupostos da primeira. Diante disto, elucidar, sucintamente, sobre os aspectos da autonomia administrativa, financeira/orçamentária e a normativa, dos quais estão assentados sobre a premissa da técnica e da especialidade do órgão regulador. Uma vez consolidado a autonomia das Agências, abordar as formas políticas e econômicas do fenômeno da captura, seja no momento de sua composição ou em sua atuação, deslegitimando e tonando a atividade regulatória ilegal, caracterizando a corrupção da agência como instrumento de proveito para determinados grupos e indivíduos, evidenciando a não superação do patrimonialismo brasileiro.

Preliminarmente, pretende-se fazer a distinção entre o que seja a autonomia e a independência das agências reguladoras. No campo doutrinário contata-se que não há diferenciação entre as ambas nomenclaturas. Diversos autores utilizam a independências das agências como sinônimo da autonomia delas. Porém, o trabalho em tela tem uma especial atenção ao tratar sobre ambos os termos. Primeiramente, entende-se que "quando se fala em autonomia, não se pode ampliar esse conceito para equipará-lo a soberania, independência ou outros sentidos inadequados para caracterizar o regime jurídico das autarquias." (DI PIETRO, 1999, p. 46). O autor Fernando Quadros da Silva (2004, p. 92) expõe pensamento análogo ao da Professora Maria Sylvia Di Pietro, ao elucidar a seguinte contribuição:

Contudo, deve-se estabelecer a nítida distinção entre autonomia e a independência, pois esta tem a ver com a livre definição dos próprios objetivos e as grandes linhas de atuação, enquanto a autonomia diz respeito à gestão, respeitando os objetivos fixados pela Administração Central.

Portanto, chega-se à conclusão, que a autonomia é apenas um pressuposto do qual deve ser efetivado pelo próprio Estado para que as Agências Reguladoras possam exercer a atividade regulatória sem os impeditivos do Governo Federal, por isso, o regime jurídico ser autarquias sob regime especial.

Porém, a visão da independência muito tem a dizer sobre o contexto social da qual a atividade regulatória no Brasil hoje se apresenta. Primeiramente, a autonomia administrativa, 
financeira/orçamentária e a normativa são espécies do gênero da independência. Há também de considerar-se que o Brasil é país construído sob a exige do capitalismo dependente ${ }^{10}$ e uma administração ainda muito patrimonialista ${ }^{11}$. Deste modo, o fenômeno da captura possui raízes profundas dentro do cenário brasileiro, impedindo a real independência da atividade regulatória por meio das agências. Portanto, as agências reguladoras devem ser autônomas (dentro do âmbito da Administração Pública) e Independente (livre para regular sem as interferências políticas e econômicas) para poder agir em prol do interesse coletivo e fomentar a livre-concorrência e o equilíbrio de mercado.

Importante aspecto a ser abordado neste tópico condiz as limitações e a autonomia das Agências no âmbito jurídico brasileiro. Assim, compreende-se que a autonomia tem que ser administrativa, financeira/orçamentária e normativa.

Dentro das especificações sobre a autonomia administrativa, faz-se oportuno analisar sucintamente sobre o mandato dos dirigente (não coincidente com o mandato político), como também, a quarentena e, por fim, a ausência de controle hierárquico. Essas particularidades serão ilustradas quando for analisado a Lei Geral das Agências Reguladoras (Lei $\mathrm{n}^{\circ}$ 13.848/19). Conforme o próprio regime jurídico das autarquias especiais, as agências possuem competência de organizar a sua própria gestão, conforme o ministro Luís Roberto Barroso (2002, p.124) aduz:

No geral, a lei endossa as linhas de entendimento que se haviam cristalizado na doutrina, prevendo: (i) nomeação de conselheiro ou diretor, pelo Presidente da República, com aprovação do Senado Federal, atendidos os requisitos da nacionalidade brasileira, reputação ilibada, formação universitária e elevado conceito no campo de especialidade dos cargos (arts. $5^{\circ}$ ); (ii) quarentena, com o impedimento ao ex-dirigente, terminado o mandato, de prestar qualquer tipo de serviço no setor público ou nas empresas integrantes do setor regulado pela agencia (art. $8^{\circ}$ ); (iii) estabilidade: os conselheiros e diretores somente perderão o mandato em

\footnotetext{
${ }^{10}$ Há 2 (dois) autores - Celso Antônio Bandeira de Mello (2016, p.1104), Celso Furtado (1974, p.17) coincidem na conclusão de que o Brasil vive em um contexto de um país periférico, no qual possui sua economia atrelada aos países centrais como também, atualmente, as transnacionais. Uma vez que o Brasil durante o período histórico nunca conseguiu desenvolver plenamente o seu setor industrial, incapacitando de criar mercados fortes e, consequentemente, uma política e agenda econômica forte o suficiente para combater interesses privados ou de grupos economicamente fortes. Um exemplo nítido a ser citado é grande parte dos países da américa latina terem seu desenvolvimento dependente aos financiamentos do FMI, tornando-os reféns das políticas de juros, enquadrando-os como países periféricos do capitalismo contemporâneo.

${ }^{11}$ O Professor de Ciências Sociais, Armando BOITO JUNIOR (2002, p. 29) expõe como o Estado sob a égide do capitalismo periférico somado ao clientelismo brasileiro, os membros decadentes da classe dominante utilizaram a máquina da administração pública como abrigo e "profissão", enquanto outros a utilizava como moeda de compra para o apoio político. Assim, dentro do capitalismo periférico o Estado é patrimonialista e serve aos interesses privados.
} 
caso de renuncia, de condenação judicial transitada em julgado ou de processo administrativo disciplinar (art. $9^{\circ}$ )

Vale ressaltar que o mandatos dos dirigentes é não coincidente ao Chefe do Poder Executivo (quem nomeia e, posteriormente, é sabatinado pelo Senado), além que as próprias leis das Agências dispõe sobre a composição de um colegiado para a análise da política regulatória, no qual permite maior pluralismo de ideias (MARQUES NETO, 2005, p. 59). Isso se deve, porque a atividade regulatória não pode ficar à mercê dos interesses políticos, o que poderia gerar a sua captação na modalidade política.

A respeito da quarentena, a doutrina juntamente com as Leis instituidoras das Agências dispõem sobre esse aspecto. Remete-se ao período de vacância que o dirigente ou membro do colegiado deve manter-se neutro ao setor regulado por um período de 6 meses (intervalo no qual será ressarcido - a caráter indenizatório - pela própria agência) para não ser captado por alguma empresa do setor do qual estava regulando, impedindo o que se chama de assimetria da informação ${ }^{12}$. Também merece destaque a garantia da estabilidade do cargo do dirigente que é de 4 anos, não podendo o Presidente da República o destituir, evitando a captura política (BARROSO, 2002, p. 124). Tais condições, somadas a ausência do controle hierárquico são pacificadas ao entendimento jurídico, pois entendeu o legislador a necessidade desta autonomia administrativa para gerar um ambiente propicio à atividade regulatória.

A respeito da autonomia financeira e orçamentária, as agências possuem "além das dotações orçamentárias gerais, a arrecadação de receitas provenientes de outras fontes, tais como taxas de fiscalização e regulação, o ainda participações em contratos e convênios" (BARROSO, 2002, p. 125). Faz-se imprescindível um orçamento próprio do qual a agência possa dispor, pois "a pior captura que pode acometer uma agência é aquela de engessar suas funções por falta de meios adequados ao seu exercício, transformando-a num simulacro" (MARQUES NETO, 2005, p. 78). Assim, a falta de recursos impediria as agências de sua finalidade, subordinando-a as empresas privadas ou outras instituições (JUSTEN FILHO (2002, p. 480).

\footnotetext{
${ }^{12}$ Entende-se que assimetria da informação seria quando alguma empresa do Setor Regulado possui mais informações que a própria agência, gerando um favorecimento informacional a empresa da qual detém maior conteúdo informacional para a tomada de decisões antecipando e prevendo alguma regulação no setor, aferindo diretamente na competitividade do setor e desqualificando a atividade regulatória. $\mathrm{O}$ fenômeno da captura por meio da técnica se dá por meio deste artifício (MARQUES NETO, 2005, p. 62)
} 
Por fim, a autonomia normativa é a última a ser analisada. Tal mérito é extremamente discutido pelos doutrinadores, vez que há entendimentos dos desrespeitos constitucionais dos princípios da separação dos poderes e da legalidade (ARAUJO, 2002, p. 55). Sem prolongar as discussões concernentes a ilegalidade dos atos normativos das Agências, o Art. 49, inciso $\mathrm{V}^{13}$, da Constituição Federal, dispõe a delegação legislativa do Congresso Nacional, assim como o controle externo desempenhado pelo Poder Legislativo contra qualquer ato exorbitante de qualquer Ente direto e indireto da Administração Pública (MORAES, 2002, p. 29). O entendimento do artigo, compreende que a atividade normativa faz-se necessária para a atividade regulatória, pois se assim não o fosse, a captura política seria de fácil alcance, além de legalizar juridicamente tal fenômeno, dificultando os interesses coletivos da atividade regulatória. Portanto, por meio de suas competências deve a Agências regular e, não apenas regulamentar ${ }^{14}$, o setor por meio da técnica e especialidade, da qual conferem a sua legitimidade.

Buscou-se até aqui elucidar a importância da autonomia para a aferição da independência das Agências Reguladoras, mostrou-se taxativamente e exemplificadamente os alcances que a falta de qualquer pressuposto aqui citados poderiam gerar e intensificar o fenômeno da captura. Porém, infelizmente mesmo com todos os instrumentos jurídicos positivados e pacificados, o instituto das agências reguladoras não possuem independência para gerar o fim pretendido. Seja pela falta de efetividade nos pressupostos da própria autonomia aqui citados ou por meio de outros artifícios, sejam políticos ou econômicos, que impossibilitam uma política regulatória que condiz aos interesses gerais da população.

O fenômeno da captura pode ser identificado tanto em sua composição e em sua atuação. A fim de trazer uma definição geral sobre o fenômeno da captura, o doutrinador Marçal Justen Filho (2002, p. 369-370) ressalta:

A doutrina cunhou a expressão captura para indicar a situação em que a agência se transforma em via de proteção e benefício para setores empresariais regulados. A captura configura quando a agência perde a condição de autoridade comprometida com a realização do interesse coletivo

\footnotetext{
${ }^{13}$ Art. 49. É da competência exclusiva do Congresso Nacional:

$\mathrm{V}$ - sustar os atos normativos do Poder Executivo que exorbitem do poder regulamentar ou dos limites de delegação legislativa;

${ }^{14}$ A regulação tem sentido mais amplo do que regulamentação. A regulação pressupõe uma participação conjunta entre os atores sociais construindo ambientes esperados. Já a regulamentação seria a produção de norma geral e abstrata, não conferindo um caráter dinâmico ao processo regulatório. Assim, a segunda é espécie do gênero da segunda (TOJAL, 2002, p. 159)
} 
e passa a produzir atos destinados a legitimar a realização dos interesses egoísticos de um, alguns ou todos os segmentos empresariais regulados. A captura da agência se configura, então, como mais uma faceta do fenômeno de distorção de finalidades dos setores burocráticos estatais.

O primeiro momento que há captação é em sua composição, pois está mais atrelada as escolhas políticas que determinam os dirigentes a serem escolhidos para a gestão das Agências. Tal fenômeno é derivada ao, não superado, patrimonialismo brasileiro. Assim, a corrupção desses Entes é uma das formas da qual ocorre o fenômeno da captura política. Ao tentar elucidar a temática trazida, há 2 (dois) exemplos dos quais há uma percepção de que a captura política é sintomática no Brasil. A primeira constatação deriva de uma pesquisa realizada pelo instituto da FGV/SP do qual demostra que apenas 58\% dos indicados possuem trajetória profissional relacionada à área regulada, sendo 90\% ligados ao perfil estatal. Ainda, apenas $6 \%$ dos nomeados vêm da iniciativa privada e, somente, $10 \%$ dos dirigentes nunca tinham exercido cargos de comissão (WIZIACK, 2016). A fim de elucidar numericamente, a seguinte tabela traz a relação entre os diretores e seu perfil estatal.

\begin{tabular}{|l|l|}
\hline \multicolumn{2}{|c|}{$\begin{array}{c}\text { Origem dos nomeados para cargos de direção nas } \\
\text { Agências Reguladoras federais selecionadas }\end{array}$} \\
\hline Agências Reguladoras & $25 \%$ \\
\hline Ministérios & $23 \%$ \\
\hline Outros órgãos e entes do Estado & $15 \%$ \\
\hline Empresa estatal & $12 \%$ \\
\hline Academia & $10 \%$ \\
\hline Iniciativa privada & $6 \%$ \\
\hline Senado Federal & $6 \%$ \\
\hline Outros & $3 \%$ \\
\hline $\begin{array}{l}\text { Fonte: GRP - FGV Direito SP (SALAMA, BARRIONUEVO, } \\
\text { 2016) }\end{array}$ \\
\hline
\end{tabular}

\footnotetext{
${ }^{15}$ Nota: Na categoria “outros órgãos e entes do Estado" estão reunidos órgãos e entes estatais não listados, como o IPEA, o Legislativo municipal e órgãos de Governo estadual. A categoria "outros" abrange outras entidades não estatais que não se enquadram na categoria "iniciativa privada", quais sejam: advocacia (2\%) e associação internacional (1\%) (SALAMA, BARRIONUEVO, 2016).
} 
Já a segunda constatação para ratificar a argumentação trazida, é sobre a corrupção da Agência Nacional das Águas. O Ministério Público em 2012 constatou a presença de pareceres fraudulentos por parte das Agências para beneficiar grupos específicos ligados ao, então Diretor da ANA, Paulo Rodrigues Vieira e seu irmão, Rubens Carlos Vieira (PIZA, 2012).

Portanto, tem-se as Agências reguladoras capturadas para fins egoísticos no momento da nomeação por meio da política, configurando a maior afronta e disfunção da atividade regulatória.

O segundo momento da captura seria em sua atuação. Nesta ocasião, a captura é feita pelos setores regulados, pois estes possuem maior número de possibilidades para se organizarem com o intuito de gerar condições favoráveis a sua demanda. Entre as possibilidades de captura, a corrupção continua sendo uma das formas (por exemplo, utilizar a Agência para impedir a comercialização de um produto em detrimento de outro ou, então, impor tarifas ao consumidor sobre um determinado serviço a fim de conferir maior lucro as empresas do setor regulado), a outra seria a assimetria da informação a mais comum entre elas. Assim, destaca-se:

Desse modo, e em termos sucintos, é possível afirmar que as agências reguladoras independentes são mais suscetíveis à ocorrência de captura porque (i) nelas há lugar para a formação de espaços de frouxidão, no quais os responsáveis pela regulação podem atuar estrategicamente; (ii) as características dos grupos formados por agentes econômicos regulados permitem que se organizem mais facilmente; (iii) é infestável a assimetria informacional entre o regulador e regulados, sendo que, muitas vezes, a informação necessário à regulação é detida, tão-somente, pelo grupo de regulados; e (iv) as agências precisam afastar a possibilidade de que as normas por elas editadas sejam simplesmente desconsideradas pelos destinatários. Enquanto na primeira situação há uma conduta voluntária e consciente do regulador no sentido de se afastar da regulação adequada ao caso concreto com vistas a tutelar interesses pessoais, nas hipóteses restantes essa dado não ocorre necessariamente, ou seja, nos três últimos casos, é possível que o regulador esteja bem-intencionado (e a captura ocorra inconscientemente). BAGATIN (2010, p. 196):

Portanto, a simples efetivação da autonomia das agências a fim de garantir a independência de sua atividade regulatória não é suficiente dentro do contexto brasileiro, no qual o fenômeno da captura toma as mais diferentes formas, seja em sua composição ou atuação. O marco legal das Agências Reguladoras, Lei no 13.848 de 2019 traz instrumentos, já existentes nas Leis Instituidoras, ampliam a governança pública e o accountability como 
formas a fim de garantir maior eficiência das atividades desenvolvidas, além de regular sobre o dever da publicidade e da transparência, que são os norteadores da proposta do Estado Republicano.

\section{A NOVA LEI GERAL DAS AGÊNCIAS REGULADORAS: LEI No 13.848 DE 2019 E O EXAME A INDEPENDÊNCIA DAS AGÊNCIAS.}

Durante muito tempo, desde a criação da primeira agência reguladora (Aneel em 1996), além das outras 10 (onze) ${ }^{16}$ que compõe o quadro das Agências Reguladoras em âmbito federal, não se tem um marco legal que regule sobre as Agências Reguladoras. Entre as principais críticas, acredita-se que a ausência de um marco legal traz insegurança jurídica as atividades regulatórias concedidas pelas Agências, além de dificultar um possível potencial de atrair recursos e desenvolver uma política nacional e conjunta de regulação. Diante de tal carência, em 25 de Junho de 2019 foi sancionado a Lei $n^{\circ} 13.848$ no qual dispõe sobre a gestão, a organização, o processo decisório e o controle social, alterando as Leis Instituidoras das Agências Federais e uniformizando a sua processualidade em âmbito federal.

A Lei 13.848 de 2019 traz alterações no que concerne sobre a gestão, a organização, o processo decisório e o controle social das agências. Assim, no Capítulo I (Do Processo Decisório das Agências Reguladoras) traz sobre a realização da Análise de Impacto Regulatório (AIR) indicando a introdução da Governança Pública nas Agências Reguladoras. Assim, como em seu Capítulo II (Da prestação de Contas e do Controle Social) introduz a pratica do accountability dentro da administração pública, nas práticas de promover maior transparência e controle social (Art. $15, \S 1^{\circ}$, inciso I). Portanto, dentro da atual lógica dos preceitos de maior eficiência, a Lei 13.848/19 traz os imperativos da boa gestão dentro das empresas para o seio da administração pública. Isso reflete em um atrativo para investimentos e a importância disto é feita dentro da atividade regulatória:

Investimentos em setores de infraestrutura possuem longo prazo de maturação e são direcionados para ativos com utilização específica, o que

\footnotetext{
16 Agência Nacional de Energia Elétrica (Aneel); a Agência Nacional de Petróleo, Gás Natural e Biocombustíveis (ANP); a Agência Nacional de Telecomunicações (Anatel); a Agência Nacional de Vigilância Sanitária (Anvisa); a Agência Nacional de Saúde Complementar (ANS); Agência Nacional de Águas (ANA); a Agência Nacional de Transportes Aquaviários (Antaq); a Agência Nacional de Transportes Terrestres (ANTT); a Agência Nacional do Cinema (Ancine); a Agência Nacional de Aviação Civil (ANAC); a v de Mineração (ANM).
} 
eleva o risco de perda futura no poder de barganha em negociações com o governo. Essa particularidade é relevante, tendo em vista que a presença de significativas economias de escala e escopo implica na necessidade de uma maior intervenção regulatória do governo. Neste contexto, a estabilidade e confiança no arcabouço regulatório reduzem a percepção de risco por parte dos investidores e podem estimular uma maior participação do setor privado em projetos de infraestrutura. (TIKIAKI, 2012, n.p.)

A fim de elucidar sucintamente em termos gerais sobre a Lei Geral das Agências Reguladoras, tratar-se-á sobre os Capítulos e suas disposições de acordo com o recorte proposto neste estudo.

O Primeiro Capítulo (Art. $1^{\circ}$ ao Art. 13) dispõe sobre a gestão e o Processo Decisório das Agências. A lei em tela busca compatibilizar e regulamentar os procedimentos sobre as questões deliberativas (Reuniões Deliberativas, consultas públicas e audiências públicas), esta regulamentação somada à Análise de Impacto Regulatória trazem estabilidade e maior transparência para uma tomada de decisões conjuntas e uniformizando os processos das Agências para que sejam efetivadas ações conjuntas entre as Agências Reguladoras (federais e estaduais), os Órgãos de Defesa da Concorrência, do Sistema Nacional de Defesa do Consumidor e do Meio-Ambiente. A Lei $\mathrm{n}^{\circ} 13.848$ converge com os interesses descritos com a participação social e o controle social, além de trazer segurança jurídica e a governança pública. Porém, o art. $3^{\circ}, \S 2^{17}$ revela uma afronta à autonomia administrativa, vez que as Agências Reguladoras estariam subordinadas pela tomada de decisões ao Ministério da Economia, o que reflete a incompatibilidade com a Independência de dispor sobre as suas competências.

O Capítulo II (Da prestação de contas e do Relatório Anual de Atividades) da referida Lei trata sobre o controle externo e a prestação de contas sobre suas atividades. Assim, a Agência deve publicar sobre o Plano Estratégico e o Plano de Gestão Anual. Ambos relatórios refletem em um maior controle e publicidade das próprias atividades da Agência,

${ }^{17} \S 2^{\mathrm{o}}$ A autonomia administrativa da agência reguladora é caracterizada pelas seguintes competências:

I - solicitar diretamente ao Ministério da Economia:

a) autorização para a realização de concursos públicos;

b) provimento dos cargos autorizados em lei para seu quadro de pessoal, observada a disponibilidade orçamentária;

c) alterações no respectivo quadro de pessoal, fundamentadas em estudos de dimensionamento, bem como alterações nos planos de carreira de seus servidores;

II - conceder diárias e passagens em deslocamentos nacionais e internacionais e autorizar afastamentos do País a servidores da agência;

III - celebrar contratos administrativos e prorrogar contratos em vigor relativos a atividades de custeio, independentemente do valor. 
estabelecendo metas e avaliando a gestão da Autarquia. Tal regulamentação é positiva à analise deste estudo, vez que traria a busca de resultados e eficiência na atividade regulatória.

Os Capítulos III ao VI estimula a possibilidade de cooperação entre os diversos órgãos reguladores e dos órgãos de proteção da concorrência, do consumidor e do meioambiente. Permite também o Termo de Ajustamento de Conduta (art. 31 ao 33) entre a Agência e pessoas físicas ou jurídicas sujeitas a sua competência. Também, reafirma e incita a troca de informações e políticas com os órgãos de defesa para uma atuação conjunta do setor regulado, permitindo maior permeabilidade e diminuindo o fenômeno da captura na forma da assimetria da informação.

Vale ressaltar algumas dissonâncias entre o estudo proposto com base na doutrina e nas Leis Instituidoras das Agências e a nova Lei no 13.848 de 2019. Primeiramente, no que concerne a Quarentena, a lei no 9.986/2000 (Lei que dispõe sobre os Recursos Humanos das Agências Reguladoras) dispõe sobre o período de 4 meses de quarentena, porém a nova lei discordando sobre essa disposição e ratificando o entendimento doutrinário, estabeleceu em 6 meses o período de quarentena, a fim de impedir a captação econômica do setor regulado. Nas disposições gerais (Capítulo VII) fez diversas alterações no mandato dos dirigentes em diversas Agências Reguladoras (Art. 36 ao 44) contrariando sobre a não-coincidência dos mandatos ilustrado no tópico anterior.

Portanto, entenda-se que a presente Lei traz bons institutos sobre a Gestão Administrativa com o contexto empresarial atual. Oportuniza e regulamenta sobre a cooperação mutua de diversos órgãos e preza pela transparência e pelo controle social. Contudo, há algumas disposições que divergem sobre a autonomia administrativa e sobre o mandato dos dirigentes. Há de se analisar como a Lei Geral das Agências Reguladoras irá impactar sobre a atividade regulatória no contexto brasileiro.

\section{CONCLUSÃO}

O delineamento proposto no artigo visou em estabelecer a natureza jurídica e o regime jurídico das agências regulados. A fim de delimitar o recorte, entende-se que ambas características definem-na como autarquias de regime especial. Assim, tem-se a autonomia na seara administrativa, financeira/orçamentária e normativa como garantia para o seu funcionamento. 
Porém, a sua independência não restringe-se apenas à efetivação de sua autonomia, sendo esta totalmente necessária para a atividade regulatória independente. Daí, surge a problemática do tema proposto: o Fenômeno da Captura. A captação de interesses individuais ou de grupos econômicos geram o Fenômeno da Captura em suas duas modalidades: a política e a econômica. Normalmente, a captura política revela-se sobre a forma da corrupção e a captura econômica, também na forma de corrupção e, na assimetria da informação. Sendo a primeira corriqueiramente no momento da composição e, a segunda no momento de sua atuação.

Assim, a independência que é o objetivo finalístico a ser alcançado como reprodução dos interesses sociais, além de gerar ambientes competitivos entre as empresas do setor regulado, apenas seria garantida se não existissem essas formas de captura. Uma maneira de impedir tal fenômeno seria a consolidação da participação e controle social na construção e das decisões deliberativas das agências, sendo a transparência instrumento imprescindível para aproximar os interesses sociais dos cidadãos.

No contexto atual, a Lei $\mathrm{n}^{\mathrm{o}} 13.848$ de 2019 traz aspectos importantes para a consolidação e uniformidade em nível federal dos pressupostos da transparência e do controle social, porém, observa-se que tal lei também contém falhas ao restringir a sua autonomia ao Ministério da Economia, podendo ser capturada pelo Governo Federal e sendo impedida de desenvolver políticas regulatórias independentes.

Em conclusão, a atividade regulatória ainda carece de instrumentos para o envolvimento social e reafirmação do interesse público nas demandas regulatórias. O pacto social entre a sociedade civil, o setor regulado e o Estado deve ser fortalecido para alcançar o então almejado Estado Republicano e Participativo.

\section{REFERÊNCIAS BIBLIOGRÁFICAS}

BAGATIN, Andreia Cristina. O problema da captura das Agências Reguladoras

Independentes. Dissertação de Mestrado da Faculdade de Direito de São Paulo, 2010.

BARROSO, Luis Roberto Barroso. Curso de direito constitucional contemporâneo: os fundamentos constitucionais e a Constituição do novo modelo. São Paulo: Saraiva. 2009.

, Luis Roberto. Apontamentos sobre as agências reguladoras. In: MORAES, Alexandre. (Org) et alli. Agências reguladoras. São Paulo: Atlas, 2002. p. 111-112. 
BRESSER-PEREIRA, Luiz C. Construindo o Estado Republicano: democracia e reforma da gestão pública; tradução: Maria Cristina Godoy. - Rio de Janeiro: Editora FGV, 2009.

BRASIL. Constituição (1988). Constituição da República Federativa do Brasil. Brasília, DF: Senado Federal: Centro Gráfico, 1988.

Decreto-Lei n⿳0 200. Dispõe sobre a organização da Administração Pública, estabelece diretrizes para a Reforma Administrativa. Brasília: Presidência da República, 1966.

. Lei n ${ }^{\circ}$ 9.986. Dispõe sobre a gestão de recursos humanos das Agências Reguladoras e dá outras providências. Brasilia: Presidência da República, 2000.

Lei $\mathbf{n}^{0}$ 13.848. Dispõe sobre a gestão, a organização, o processo decisório e o controle social das agências reguladoras, altera a Lei $\mathrm{n}^{\circ}$ 9.427, de 26 de dezembro de 1996, a Lei $\mathrm{n}^{\circ}$ 9.472, de 16 de julho de 1997, a Lei ${ }^{\circ}$ 9.478, de 6 de agosto de 1997, a Lei $\mathrm{n}^{\circ}$ 9.782, de 26 de janeiro de 1999, a Lei no 9.961, de 28 de janeiro de 2000, a Lei n ${ }^{\circ}$ 9.984, de 17 de julho de 2000, a Lei $\mathrm{n}^{\circ} 9.986$, de 18 de julho de 2000, a Lei $\mathrm{n}^{\circ} 10.233$, de 5 de junho de 2001, a Medida Provisória $n^{\circ}$ 2.228-1, de 6 de setembro de 2001, a Lei n ${ }^{\circ} 11.182$, de 27 de setembro de 2005, e a Lei n ${ }^{\circ}$ 10.180, de 6 de fevereiro de 2001: Presidência da República, 2019.

DI PIETRO, Maria Sylvia Zanella. Direito Administrativo. 13. ed. São Paulo: Atlas, 2001.

FURTADO, Celso. O mito do desenvolvimento econômico. Rio de Janeiro: Editora Paz e Terra S/A. 1974

JUSTEN FILHO, Marçal. O direito das agências reguladoras independentes. São Paulo: Dialética, 2002

MARQUES NETO, Floriano Peixoto de Azevedo. Regulação Estatal e Interesses Públicos. São Paulo: Malheiros, 2002.

MARQUES NETO, Floriano de Azevedo. Agências Reguladoras Independentes: fundamentos e seu regime jurídico. Belo Horizonte: Fórum, 2005.

MEIRELLES, Hely Lopes. Direito Administrativo Brasileiro, São Paulo: Malheiros, 42. ed., 2016, 968 p.

MELLO, Celso Antônio Bandeira de. Curso de Direito Administrativo. 26. ed. São Paulo: Malheiros, 2009. 
MORAES, Alexandre de. Agência Reguladoras. 1. ed. São Paulo: Editora Atlas, 2002. v. 1.

PIZA, Paulo Toledo. Globo. PF prende dois diretores de agências reguladoras e indicia 18 por fraudes. G1.Globo, São Paulo: 2012. Disponível em: < http://g1.globo.com/saopaulo/noticia/2012/11/pf-indicia-18-por-fraudes-em-pareceres-tecnicos.html. Acesso em: 02 jul 2012.

SALAMA, Bruno Meyerhof; BARRIONUEVO, Arthur (Coord.). Dinâmica de nomeações das agências reguladoras. São Paulo: Escola de Direito da Fundação Getúlio Vargas, 2016. Disponível em:

$<$ https://www.google.com/url?sa=t\&rct=j\&q=\&esrc=s\&source=web\&cd=2\&cad=rja \&uact=8 \&ved=2ahUKEwjmwPSq9rDfAhVGHpAKHU0RAvAQFjABegQICBAC\&url=https\%3A\%2 F\%2Fportal.fgv.br\%2Fsites\%2Fportal.fgv.br\%2Ffiles\%2F02_grp_-_relatorio_de_pesquisa__nomeacao_de_dirigentes_nas_agencias_reguladoras_sponsor.pdf\&usg=AOvVaw0g5fWORY4WaR4G6pfYxPS>. Acesso em: 29 ago. 2019.

SILVA, Cláudio Eduardo Regis de Figueiredo. Administração Gerencial e A Reforma Administrativa no Brasil. Curitiba: Juruá, 2004. 226 p.

SILVA, Fernando Quadros da. Agências Reguladoras: a sua independência e o princípio do estado democrático. $1^{\circ}$ ed. Curitiba: Juruá, 2010. 174 p.

TIRIAKI, Gisele Ferreira. A independência das agências reguladoras e o investimento privado no setor de energia de países desenvolvidos. Econ. Apl. vol.16 no.4 Ribeirão Preto Oct./Dec. 2012. http://dx.doi.org/10.1590/S1413-80502012000400007

TOJAL, Sebastião Botto de Barros. Controle judicial da atividade normativa das agências reguladoras. In: MORAES, Alexandre de (org.). Agências reguladoras. São Paulo: Atlas, 2002 .

WIZIACK, Julio. Agências Reguladoras acabam capturadas pelo governo, diz FGV. Folha de São Paulo, São Paulo: 2016. Disponível em: < http://www1.folha.uol.com.br/mercado/2016/07/1787449-agencias-reguladoras-acabaramcapturadas-pelo-governo-diz-fgv.shtml>. Acesso em: 02 jul 2017 